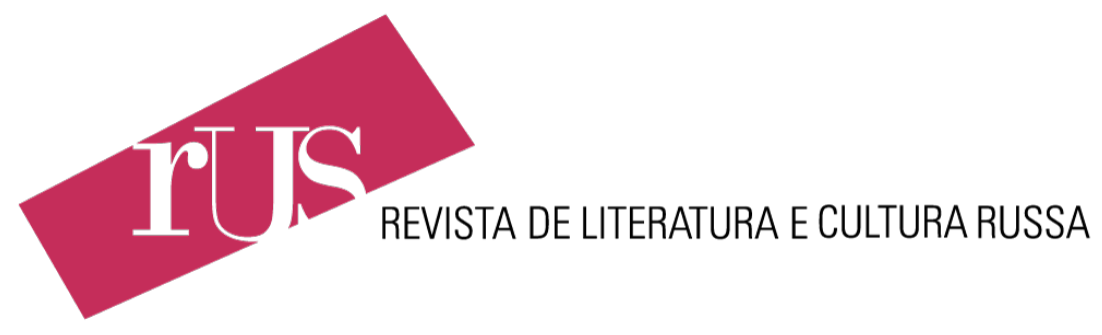

\title{
As perspectivas de um método
}

\section{The perspectives of a method}

\author{
Autor: Modesto Carone \\ Edição: RUS Vol. 12. № 19 \\ Publicação: Agosto de 2021 \\ https://doi.org/10.11606/issn.2317-4765.rus.2021.188667
}




\section{As perspectivas de um método ${ }^{1}$}

*Modesto Carone (1937-2019) foi professor de literatura e cultura brasileiras na Universidade de Viena, professor de literatura e teoria literária na Universidade de Campinas e na Universidade de São Paulo. Foi um renomado tradutor da obra de Franz Kafka para o português.
Modesto Carone*

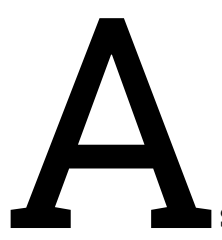

Teses de 1929 resultam de um trabalho coletivo cujas origens remontam, de fato, a 6 de outubro de 1929. Nesta data reuniram-se em Praga, sob a presidência do filólogo V. Mathesius, três linguistas tchecos - B. Havránek, J. Rypka e B. Trnka - e um russo: Roman Jakobson. Fundava-se, nesse dia, o Círculo Linguístico de Praga, de cujas atividades iriam participar, na qualidade de membros ou correspondentes, outros pesquisadores eminentes, como J. Mukařovský, N.S. Trubetskói, B. Tomachévski, B. Bogatyrev, René Wellek e I. Tyniánov.

1 Este texto foi originalmente publicado em 1978 como introdução ao livro Círculo Linguístico de Praga, organizado e publicado pelo professor Jacó Guinsburg. Agradecemos a André Carone e Gita Guinsburg a autorização para republicá-lo nesta edição especial da RUS. (GUINSBURG, J. (org.). Círculo Linguístico de Praga. São Paulo: Editora Perspectiva (Coleção Elos), 1978, p.11-16. 
A convergência de esforços e interesses que animava o Círculo deu motivo a que ele fosse descrito como uma "simbiose de trabalhos" entre russos e tchecos. O elemento de ligação entre as duas comunidades científicas tinha sido Jakobson, que desde 1920 vivia em Praga. O linguista russo já se destacara como presidente do Círculo Linguístico de Moscou, com o qual mantivera ativa cooperação a célebre Opoiaz - Sociedade de Estudos da Linguagem Poética. A relevância dos debates moscovitas, que coincidia com um período de grandes transformações da sociedade russa, pode ser avaliada pela participação, neles, não só de críticos e teóricos de Literatura como Eikhenbaum e Chklóvski, mas também de poetas do porte de Maiakóvski e Mandelstam. O foco de convergência dessa brilhante geração de pesquisadores era a linguagem, sobretudo sua manifestação menos atendida pelos estudiosos da matéria - a poesia. Esta continuava sendo, em larga medida, uma vaporosa questão de sensibilidade, a que não deviam ter acesso os instrumentos da razão, para que não se destruísse sua aura nem, porventura, o preconceito de classe que adere a uma concepção aristocrática da arte. A poesia, entretanto, ajustava-se perfeitamente ao tipo de pesquisa visado pelos membros do Círculo de Moscou e da Opoiaz, pois eles percebiam que era justamente nela que se evidenciava o aspecto realmente criador da linguagem e - acrescentaríamos agora - o seu poder de revelação do real. Em termos históricos e metodológicos, no entanto, o corolário desta atenção minuciosa aos mecanismos internos da linguagem poética foi um isolacionismo estético que marcou boa parte da atividade teórica dos formalistas (como eles foram chamados e o uso acabou por consagrar, embora a mesma pecha tenha sido atribuída a "insuspeitos" como Maiakóvski e, posteriormente, Brecht). O problema ainda é pertinente e atual, mas não cabe, no espaço estreito deste comentário, retraçá-lo. Fique, no entanto, assinalada a observação de que muitas boutades dos formalistas russos não devem ser confundidas com os resultados objetivos de sua pesquisa. Bukharin, um dos seus críticos, em discurso pronunciado em 1934, no Congresso de Escritores Soviéticos, após condenar o formalismo extremo, que retira a 
arte do seu contexto social, já advertia sobre a utilidade, e até mesmo o caráter indispensável, de uma análise da forma, num momento como aquele, em que a tarefa principal dos revolucionários consistia em dominar a técnica.

O Círculo Linguístico de Praga, que retoma e amplia as inquietações básicas do de Moscou (assediado pelo avanço da repressão cultural iniciada no final da década de 20 e completada na de 30 , em plena era stalinista), expôs o seu programa nas teses apresentadas ao I Congresso Internacional de Eslavistas de 1929. Sua ideia fundamental reside na concepção finalista da língua enquanto produto da atividade humana, ou seja, como sistema funcional de meios de articulação que servem a um fim determinado. Isso quer dizer, em outras palavras, que não se pode compreender nenhum fato de língua sem considerar o sistema ao qual ele pertence.

$\mathrm{O}$ que aqui pode parecer uma concepção estática ou a-histórica da realidade linguística - e não só dela, uma vez que a língua se insere em sistemas maiores, como a sociedade - privilegia, contudo, a flexibilidade dialética da própria História. Assim é que, para os linguistas de Praga, existe uma estreita correlação entre os dados fatuais do sistema e sua inserção no processo histórico:

a descrição sincrônica não pode excluir de maneira absoluta a noção de evolução, pois, mesmo num setor considerado sincronicamente, existe a consciência do estádio em desaparecimento, do estádio presente e do estádio em formação.

Esta visão abrangente do objeto encontra sua expressão no procedimento comparativo que subjaz a uma tal tática de pesquisa; por isso, "o estudo comparativo põe de lado, definitivamente, o método estéril e fictício da história dos fatos isolados". Não é demais lembrar que essa postura vale não só para o estudo da língua prática como também da literatura que nela se manifesta - daí sua relevância para a crítica e a historiografia literária.

Contemporaneamente a tudo isso é preciso notar, também, que o Círculo Linguístico de Praga destacou, como problema fundamental, a relação entre a língua e a realidade. A própria 
língua literária é encarada como atualização estética da linguagem enquanto fenômeno social de expressão e comunicação. Sua especificidade consiste no fato de se apresentar como uma "língua" mais desenvolvida e diferenciada funcionalmente do que a língua de comunicação corrente, devendo, nessa medida, submeter-se a uma pesquisa mais ampla de suas camadas funcionais. Na verdade, os praguenses viam, na poesia - a exemplo dos formalistas russos - um discurso orientado para o que se poderia chamar de "ressurreição da palavra". Isso implicava que, para eles, a língua poética tem normas próprias; mas é preciso considerar que tais normas são mutáveis ou, se se quiser, concretamente condicionadas. Desta forma, o destaque, para o primeiro plano, das diferenças entre a língua poética e a língua prática, indispensáveis à correta compreensão da literatura, não elimina sua relação com a vida real; antes, é através do estudo dessas peculiaridades que se pode chegar a critérios pertinentes de mediação entre o texto e a História em que ele se articula. Compreende-se, assim, a generalização no sentido de que "tudo, na obra de arte, bem como sua relação com o mundo, pode ser abordado em função do signo e do significado." É a partir daí que se pode considerar a Estética, como o fizeram os estudiosos de Praga, parte da moderna ciência dos signos. Isso significa que, para apreender a obra literária em sua totalidade, os praguenses ampliaram a área da teoria da literatura, abrindo-a às conquistas da semiótica. Por outro lado, para eles o conteúdo emocional ou ideológico da obra artística se erige em objeto regular da análise crítica na exata medida em que se configurem como partes componentes de uma estrutura estética. Formalismo? Certamente não: mesmo um representante tão decidido da Escola Crítica de Frankfurt, como Theodor W. Adorno, enfrenta a questão nos mesmos termos, ao afirmar que as contradições não resolvidas da realidade reaparecem na obra de arte como problemas imanentes de sua forma.

A coincidência é elucidativa porque a ideia de sistema funcional, desenvolvida em Praga, pode ser vista, em termos históricos, como expressão de uma tendência generalizada do pensamento contemporâneo. Para o Círculo Linguístico, tra- 
ta-se, de fato, de um princípio noético, portanto, que se impunha não só em Linguística, mas também em disciplinas tão diferentes como a Psicologia, a Teoria da Literatura, a Sociologia e a História da Arte. Se o termo "sistema" ou "estrutura" passou a recobrir ideologicamente procedimentos que negavam a História nos seus pressupostos e resultados, talvez a responsabilidade pelo desvio não devesse recair nos ombros dos pesquisadores que compunham o Círculo de Praga ou seus continuadores mais sérios, mas coubesse aos processos de banalização a que mesmo concepções transformadoras do mundo, como a de Marx ou Freud, até hoje estão suspeitas. É portanto com o olhar voltado para nuanças dessa natureza que devem ser abordadas as Teses de 1929, retirando delas o muito que têm de estimulante para o trabalho crítico. E vistas as coisas por este ângulo, a importância do chamado "método estrutural", que aqui se delineia, deve ser não sua relevância em si - sedução a que sucumbe muito classificador rotineiro - mas a produtividade do seu emprego no quadro geral de uma análise dialética das formas de linguagem e suas relações com o modo de ser social daqueles que a utilizam. 